\title{
The Nexus Between Adherence to Recommended Lifestyle Behaviors and Blood Pressure Control in Hypertensive Patients at Mutare Provincial Hospital, Zimbabwe: A Cross-Sectional Study
}

\author{
Samantha N Tozivepi (D) \\ Simon Takawira $\mathbb{( D}^{2}$ \\ Elliot Chikaka ${ }^{2}$ \\ Paddington Mundagowa' \\ Elizabeth M Chadambuka ${ }^{2}$ \\ Fadzai Mukora- \\ Mutseyekwa' \\ 'Clinical Research Centre, Africa \\ University, Mutare, Manicaland Province, \\ Zimbabwe; ${ }^{2}$ Department of Health \\ Sciences, Africa University, Mutare, \\ Manicaland Province, Zimbabwe
}

\begin{abstract}
Purpose: To determine the association between the achievement of blood pressure (BP) control and adherence to recommended lifestyle behaviors among hypertensive patients seen at Mutare Provincial Hospital, Zimbabwe.

Patients and Methods: A cross-sectional study was conducted using BP readings from three consecutive months. A structured interviewer-administered and pretested questionnaire with components derived from the World Health Organization Stepwise Survey was employed to extract information from 350 purposively selected participants. Measurement of BP was based on the Eighth Joint National Committee Guidelines. Bivariate and multivariate logistic regression analyses were computed using the SPSS package.
\end{abstract}

Results: The mean age of the 350 participants was $67 \pm 11.38$ years. Males made up $35 \%$ of the participants and BP control was achieved in $41.4 \%$ of the patients. Only $5.1 \%$ of the participants reported adherence to all the recommended lifestyle behaviors. Low adherence rates were reported for diet, medication, and physical activity. Bivariate analysis showed that participants who adhered to antihypertensive treatment and alcohol recommendations had reduced odds of having uncontrolled hypertension, while consuming deep-fat fried foods $\geq 3$ times a week was associated with higher odds of uncontrolled BP $(p<0.1)$. Logistic regression analysis revealed that participants who ate traditional whole-grain "sadza" or porridge were more likely to have controlled BP [adjusted odds ratio (AOR): 1.6; 95\% confidence interval (CI): 1.0-2.5] while those who did not add salt at the table had reduced odds of having uncontrolled BP by $40 \%$ (AOR: 0.6 ; 95\% CI: $0.4-0.9$ ).

Conclusion: Overall, adherence to the recommended lifestyle behaviors which are known to be effective in controlling BP in Mutare was poor. Health workers should include comprehensive health education messages on the importance of compliance with dietary, medication, and physical exercise recommendations when counseling patients. The intervention crafting process should focus on identifying enablers of the recommended lifestyle behaviors in the community and the health delivery system.

Keywords: blood pressure, adherence, diet, physical activity, hypertension, Mutare

\section{Introduction}

Initially deemed diseases of high-income countries, non-communicable diseases (NCDs) now disproportionately affect people living in low- and middle-income countries (LMICs). An increase in the prevalence of NCDs in Africa has resulted in the competition of disease priorities on strained healthcare systems already
Correspondence: Paddington Mundagowa Africa University Clinical Research Center, I32 Herbert Chitepo Street,

Mutare, Zimbabwe

Tel +263773878 II6

Email mundagowap@africau.edu 
burdened by communicable diseases. ${ }^{1-3}$ Morbidity and mortality due to NCDs are mostly attributed to the four major diseases, namely, cardiovascular diseases (CVDs), cancers, respiratory diseases, and diabetes. The World Health Organization 2018 Report on NCDs cited that the diseases caused 15 million premature deaths of people aged between 30 and 39 years with over $85 \%$ of these deaths occurring in LMICs. ${ }^{4}$

Uncontrolled hypertension, also termed high blood pressure (BP), is the major risk factor for global CVDs morbidity and mortality, causing an estimated half of the CVDs events. ${ }^{5}$ High BP is a threat to health and quality of life, and it can lead to heart attack, stroke, heart failure, kidney disease or failure, vision loss, sexual dysfunction, chest pain, and peripheral artery disease. ${ }^{6}$ Elevated BP is a "silent killer" impacting nearly one in three adults worldwide because it is asymptomatic and often detected after it has already caused considerable damage to internal body organs. ${ }^{6}$ Empirical evidence also reported that hypertension is associated with type 2 diabetes mellitus, thus diabetic screening is recommended in all people living with hypertension. ${ }^{7}$ The risk of CVDs and the associated burden of the health system could be reduced through the prevention, control, and treatment of hypertension. ${ }^{8}$

Chronic diseases such as hypertension tend to be amplified by aging, rapid unplanned urbanization, and unhealthy lifestyles. Self-management of hypertension includes adhering to prescribed medications as well as lifestyle modification behaviors like healthy diets, avoidance of cigarette smoking, physical activity, and limited or no alcohol consumption. ${ }^{9}$ The combination of dedicated lifestyle behavior modifications is efficient in lowering BP as much as taking antihypertensive medication, ${ }^{10}$ and may prevent or delay the need for additional antihypertensive medications, as well as the development of related complications. ${ }^{11}$ For this reason, many patients with stage 1 hypertension and no evidence of target organ damage can be initiated on lifestyle behavior modifications before introducing pharmacologic therapy.

The African continent has seen a gradual increase in the number of people living with hypertension from 54.6 million in 1990 to 92.3 million in 2000 to 130.2 million in 2010 and this number is projected to increase to 216.8 million by the year $2030 .{ }^{12}$ A review on hypertension in sub-Saharan Africa reported that the level of awareness of hypertension among men and women living with the disease was under $40 \%{ }^{13}$ The management of acute and chronic hypertension in sub-Saharan Africa is poor due to delays in presentation, limited access to advanced diagnostic services, lack of follow-up care. ${ }^{14,15}$ Besides, advanced care such as the decision on the antihypertensive medication to be prescribed is commonly delivered by lower-skilled health workers, especially in the rural areas.${ }^{16}$ In Zimbabwe, hypertension had a high pooled prevalence of $30 \%{ }^{17}$ (35\% in women and $24 \%$ in men living in urban settings). ${ }^{18}$ Despite intensive antihypertensive treatment, overall BP control rates of only $30 \sim 50 \%$ have been reported in patients with hypertension. ${ }^{19}$

A study conducted in another African setting that is similar to Zimbabwe revealed a prevalence of $23 \%$ in adherence to all the four recommendations under investigation and these were diet, smoking, alcohol consumption, and physical activity-related recommendations. ${ }^{20}$ A preliminary study on drug adherence behavior among hypertensive outpatients at Mutare Provincial Hospital, Zimbabwe revealed that satisfactory levels of BP control were not achieved in most hypertension patients, even those who were collecting their prescribed medications. ${ }^{21}$ This study aimed to determine the association between adherence to recommended lifestyle behaviors and BP control among hypertensive patients who were attending the chronic disease clinic at Mutare Provincial Hospital, Zimbabwe.

\section{Materials and Methods Study Design and Study Population}

This study employed an analytical cross-sectional design. The study population comprised of hypertension patients who were at least 18 years old and had been on hypertensive medication for at least 6 months. The study focused on fully conscious and stable patients and pregnant women were excluded from participating since hypertension can present as a complication of pregnancy even in women whose BP is known to be normal.

\section{Study Setting}

The study was conducted at Mutare Provincial Hospital in Manicaland Province, eastern Zimbabwe. The catchment area of the hospital covers the entire population of Manicaland Province (estimated at 1.7 million) and it serves as the province's tertiary referral facility. Chronic hypertension patients visited the hospital's Outpatients Department (OPD) monthly on the prescribed review date. In practice, the hospital staff at the OPD attended 
to over 400 hypertension follow-up cases who would have come for their routine monthly review visits. ${ }^{21}$

\section{Sampling and Sample Size}

This was a census of follow-up cases of hypertensive patients who were attended at the Mutare Provincial Hospital. Those who met the inclusion criteria, that is, having at least 18 years of age and had been on hypertensive treatment for at least 6 months before data collection were purposively selected for participation. The participants were given information on the study after they had received the intended health services. The representative sample size for the study was determined using an estimated hypertension prevalence rate of $23 \%$ from a study on adherence to all recommended lifestyle behaviors conducted in Ethiopia, ${ }^{20}$ at a $5 \%$ margin of error and $95 \%$ confidence level. Based on these assumptions, the calculated minimum sample size was 273 and after adjusting for a $20 \%$ non-response rate, the maximum sample size was 342 .

\section{Data Collection}

This study used a structured interviewer-administered questionnaire and some components of the tool were adopted from the WHO Stepwise Survey. The adopted components were used to assess uptake of recommended lifestyle behaviors (dietary habits, physical activity, alcohol consumption, and tobacco use). The researchers crafted questions to collect information on medication adherence. Measurement of BP was based on the Eighth Joint National Committee (JNC 8) guidelines which recommended that the systolic/diastolic BP (SBP/DBP) should be under $140 / 90 \mathrm{mmHg}$ for all treated hypertension individuals aged $<60$ years, those with either diabetes or chronic kidney disease while $<150 / 90 \mathrm{mmHg}$ is for those aged $\geq 60$ years for it to be regarded as controlled. ${ }^{22}$

To ascertain whether the patient's BP was controlled or not, two BP readings were taken at each visit by two different nurses, with the client rested in a relaxed sitting position using a manual sphygmomanometer. An individual's BP constantly varies, thus two measurements were taken during each visit to give a more accurate reflection of the patient's usual BP. The two BP measurements were separated by a resting interval of at least five minutes and at most 30 minutes, which was sometimes longer than the standard five minutes recommended by other studies. ${ }^{23-25}$ This delay was mainly due to a shortage of nursing staff and increased work burden at the OPD. The two BP measurements were repeated at each visit for three consecutive months. Participants were encouraged not to smoke or drink caffeinated beverages an hour before BP measurement. The average of the two BP readings (taken per visit) was recorded to be used for analysis. To examine the achievement of BP control, three consecutive monthly $\mathrm{BP}$ readings were obtained from the OPD Hypertension Register. For triangulation purposes, the recorded BP measurements in the Hypertension Register were doublechecked with the participant's outpatient records. Patients were categorized as having controlled hypertension if they had at least two of the three consecutive monthly readings being normal based on the JNC 8 guidelines.

The data collection tools were first developed in English and then translated to the vernacular languageShona and then back to English for analysis. The translation process was carried out by two blinded language experts from Africa University. Data collection was conducted in a period of five weeks from June to July 2019. Research assistants were trained on the data collection procedure and the informed consent process while the data collection tools were pretested at Mutare City Clinic using 16 hypertensive patients.

\section{Data Analysis}

Adherence or non-adherence was identified at the analysis stage. Data capturing and cleaning were done by the research assistants under the supervision of the principal investigator using Microsoft Excel. Data analysis was done by a biostatistician using Statistical Package for Social Science (SPSS) version 24 software. The findings of the descriptive statistics were expressed as percentages and frequencies. Bivariate analysis was performed for each independent variable against the outcome variable to estimate the crude odds ratios. All independent variables that were statistically significant at $\mathrm{p}<0.2$ were included in logistic regression analysis and variables with a $\mathrm{p}<0.05$ were considered to be statistically significant. After simultaneous control of the effect of other factors, multiple logistic regression analysis was used to ascertain the independent effect of the variables that were statistically significant during bivariate analysis.

\section{Ethical Considerations}

This study was conducted in accordance with the Declaration of Helsinki and written informed consent was obtained from all the participants and participation was voluntary. Ethical clearance was obtained from Africa 
University Research Ethics Committee while permission to conduct the study was obtained from the Manicaland, Provincial Medical Director, and Mutare Provincial Hospital Medical Superintendent.

\section{Operational Definitions}

Adherence: The degree of compliance with prescribed therapeutic measures, medicinal or not, aiming to maintain BP levels. ${ }^{26}$

Adherence to recommended lifestyle behavior referred to participants who followed the diet, physical activity, smoking, and alcohol, and medication recommendations.

Alcohol consumption-related adherence: participants who reported that they did not consume alcohol or who drank alcohol in moderation, that is, whose overall score on Fast Alcohol Screening Test $\leq 3$. Alcohol consumption was assessed using the Fast Alcohol Screening Test (FAST). ${ }^{27}$ The FAST score included 5 items scored from $0=$ never, $1=$ less than monthly. $2=$ monthly, $3=$ weekly and $4=$ daily/almost daily.

Consumption of a high fiber diet was assessed by asking the type of predominant mealie-meal used to cook "sadza" (thick maize-meal paste which is the local staple food) or porridge, traditional small grain "sadza" or porridge consumption, fruit, and vegetable intake.

Diet adherence: reporting daily consumption of a diet rich in vegetables, high fiber starch, and fruits; reduced sodium and saturated fat intake.

Medication adherence: included participants who never missed medication doses or took at least $80 \%$ of their prescribed medication as instructed.

Physical activity was measured by asking the client's involvement in domestic chores as well as the type of transportation they used, occupation, and deliberate routine exercise. Participants were classified as active when performed moderate to vigorous physical activity for at least $30 \mathrm{~min}$ per day, at least three times per week. Reclining or sitting time was also evaluated as a complimentary domain to physical activity and was defined by the average time the individual remained seated or reclining (minutes/day). Daily-life examples were provided to facilitate responses, such as sitting at home or work, driving, or screen time (watching television).

Saturated fat intake was assessed by asking the frequency a participant consumed fast foods or consumed food containing high animal fat per week.
Smoking-related adherence: participants who reported that they do not smoke (never smoked or stopped smoking).

Sodium intake was assessed by asking whether the client added salt to their food at the table.

\section{Results}

A total of 350 participants were interviewed and the response rate was $98 \%$. Sixty-five percent $(\mathrm{n}=228)$ were females and the majority of participants $(41.4 \%, n=145)$ were in the age group 66-75 years. The mean age of the participants was $67 \pm 11.4$ years. The overall mean SBP for all participants was $144.1 \pm 21.39 \mathrm{mmHg}$ and DBP was $83.5 \pm 13.59 \mathrm{mmHg}$. BP control was achieved in only $41.4 \%(n=145)$ of the hypertensive patients. Table 1 shows the sociodemographic characteristics of study participants.

\section{Adherence to Recommended Lifestyle Modifications}

After checking for compliance for the five recommended lifestyles, only $5.1 \%(\mathrm{n}=18)$ participants were adherent to all recommended lifestyle behaviours (diet, smoking cessation, alcohol consumption, physical exercise, and antihypertensive treatment). Of those 18 participants who were adherent to all recommended lifestyle behaviors, 11 had uncontrolled BP. Figure 1 shows the proportion of participants who adhered to the recommended lifestyle modifications. More females $(98.7 \%)$ were adherent to smoking recommendations, compared to males (93.4\%). More females (78.2\%) were adherent to whole-grain diet recommendations than males and males $(24.6 \%)$ were adherent to moderate physical activity than females $(21.9 \%)$.

Table 2 shows the association between recommended lifestyles and BP control, while Table 3 shows the results of logistic regression of the variables that were statistically significant at $\mathrm{p}<0.1$ during bivariate analysis. After controlling for confounding, consumption of traditional (whole grain) "sadza" or porridge was significantly associated with having a controlled BP, with those who ate traditional whole-grain "sadza" more likely to have a controlled BP when compared to those who did not consume the traditional whole-grain "sadza" or porridge. Hypertensive patients who did not put additional salt to food when served had $40 \%$ reduced odds of having 
Table I Sociodemographic Characteristics of Study Participants (Uncontrolled BP $n=205$; Controlled BP $n=\mid 45$ )

\begin{tabular}{|c|c|c|c|c|}
\hline Variable & Characteristic & Uncontrolled BP n (\%) & Controlled BP n (\%) & Total \\
\hline \multirow[t]{2}{*}{ Sex } & Male & $69(56.6)$ & $53(43.4)$ & $122(34.9)$ \\
\hline & Female & $136(59.6)$ & $92(40.4)$ & $228(65.1)$ \\
\hline \multirow[t]{4}{*}{ Education } & Primary & $84(57.1)$ & $63(42.9)$ & $147(42.0)$ \\
\hline & Secondary & $82(59)$ & $57(4 I)$ & $139(39.7)$ \\
\hline & Tertiary & $21(72.4)$ & $8(27.6)$ & $29(8.3)$ \\
\hline & None & $18(5)$ & $17(0.5)$ & $35(10.0)$ \\
\hline \multirow[t]{2}{*}{ Marital status } & Married & $125(6 \mid .6)$ & $78(38.4)$ & $203(58.0)$ \\
\hline & Unmarried & $80(54.4)$ & $67(45.6)$ & $147(42.0)$ \\
\hline \multirow[t]{2}{*}{ Residence } & Urban & $105(62.5)$ & $63(37.5)$ & $168(48.0)$ \\
\hline & Rural & $100(54.9)$ & $82(45.1)$ & $182(52.0)$ \\
\hline \multirow[t]{3}{*}{ Income source } & Employment & $31(59.6)$ & $21(40.4)$ & $52(14.9)$ \\
\hline & Family support & 117 (59.7) & $79(40.3)$ & $196(56.0)$ \\
\hline & Pension, church \& social support & $57(55.9)$ & $45(44.1)$ & $102(29.1)$ \\
\hline \multirow[t]{6}{*}{ Age group } & $\leq 45$ & II (73.3) & $4(26.7)$ & $15(4)$ \\
\hline & $>45-55$ & $38(77.6)$ & II (22.4) & $49(14)$ \\
\hline & $>55-65$ & $42(68.9)$ & $19(31.1)$ & $61(17)$ \\
\hline & $>65-75$ & $74(5 \mathrm{I})$ & 71 (49) & $\mid 45(4 \mid)$ \\
\hline & $>75-85$ & $35(53)$ & 31 (47) & $66(19)$ \\
\hline & $>85$ & $5(35.7)$ & $9(64.3)$ & $14(4)$ \\
\hline
\end{tabular}

uncontrolled BP when compared to their counterparts who added salt to their food when served.

\section{Discussion}

This study sought to determine the association between adherence to recommended lifestyle behaviors and BP control in hypertensive patients who attended the chronic disease clinic at Mutare Provincial Hospital, Zimbabwe. The study findings revealed a high prevalence of uncontrolled BP with poor adherence to diet, prescribed medication, and physical activity, however, adherence to smoking and alcohol intake recommendations was commendably high. Consuming traditional whole-grain mealie meal once or twice per week and not adding salt to their food at the table was associated with controlled hypertension. This study is unique because according to the authors' knowledge it is the first study to explore lifestyle behaviors associated with hypertension in eastern Zimbabwe.

The researchers noted reduced odds of having uncontrolled BP in participants who did not add salt to their food at the table. This was consistent with a Ghanaian study which showed enhanced hypertension control as a result of reduced sodium intake. ${ }^{28}$ A study on salt sensitivity of blood pressure in humans reported that excessive sodium consumption ( $>5 \mathrm{~g}$ sodium per day) increases BP, accelerates the onset of hypertension and associated cardiovascular complications. ${ }^{29}$ Other direct effects of excessive salt intake include microvascular reducing sodium intake gradually lower BP levels with time. ${ }^{30}$ It is worth noting that Sacks and others found out that for individuals who previously consumed more than average sodium, the taste buds will become accustomed to reduced salt content within about 8 to 12 weeks. ${ }^{31}$ Thus, it is imperative to educate patients, particularly those who are hypertensive to reduce their salt intake if the condition is to stay under control.

Overall, the majority of participants in this study were adherent to the whole-grain and vegetable (high fiber) diet, and consumption of whole grains was associated with increased odds of having controlled BP. This observation consistent with other studies which cited that diet-related adherence was associated with controlled hypertension, these include a meta-analysis in Zimbabwe, ${ }^{17}$ a nutrition and health survey in Japan, ${ }^{32}$ and a systematic study in the US. $^{33}$ "Sadza", also known as "tsima", "itshwala" or "phutu" (a thick mealie-meal paste), is the staple diet for the majority of Zimbabwe's indigenous people and it can be made using a variety of pulverized grains such as maize, bulrush millet, finger millet. It is consumed almost daily and sometimes twice a day in many households. 


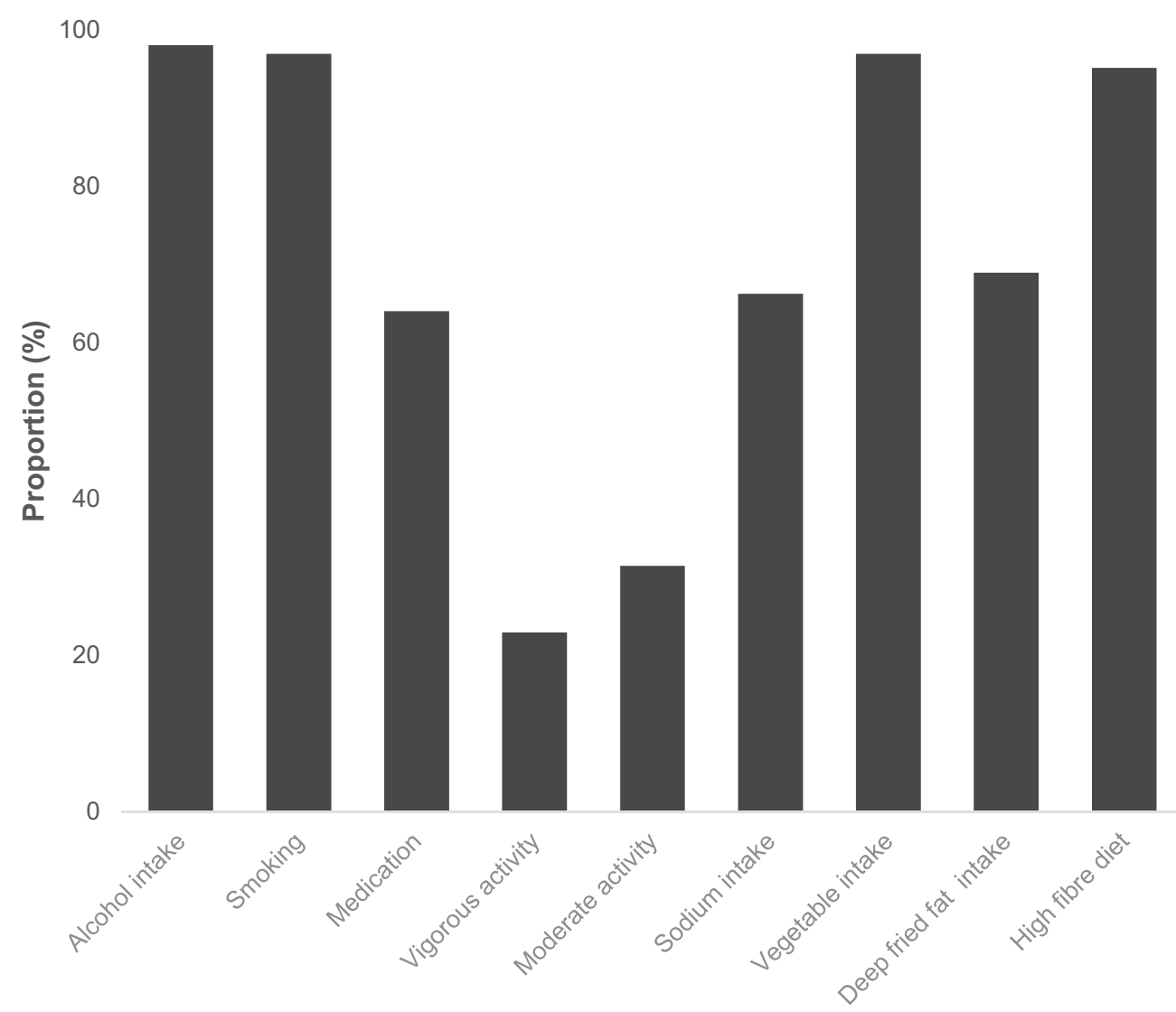

Recommended lifestyle behavior

Figure I The graph shows the proportion of study participants who adhered to recommended lifestyle behaviors.

When served with a variety of relish, it provides antioxidant phytochemicals with the possibility of mitigating chronic diseases. ${ }^{34,35}$ However, this paste ceases to provide all the essential antioxidant phytochemical particularly when overserved with limited variety of relish. ${ }^{34}$ This could be attributed to the increased proportion of participants who ate the whole-grain "sadza" more than three times a week yet their BP remained uncontrolled.

The mechanism underlying the favorable effects of the consumption of whole-grain meals on the reduction of high BP is still unclear although a study by Wang and others suggested that whole grains may lower BP by changing the gut microbiota. ${ }^{36}$ Paradoxically, the dire economic situation in Zimbabwe might have led most people to resort to eating cheaper whole-grain food like "sadza" and vegetables, partly because they no longer afford to buy food which is refined, low in fiber, and has a high content of saturated fats. ${ }^{37}$ Thus, the economic situation might have masked the true picture in terms of the actual connection between adherence to diet and hypertension control which was noted to be poor in another local study. ${ }^{38}$
Despite the relationship between fat intake and BP control not being statistically significant, nearly seven in every 10 of the participants never/rarely consumed food with saturated fats like deep fat fried food, while $49 \%$ never consumed boiled meat with high-fat content and $93 \%$ rarely/never ate from fast-food outlets or restaurants in this study. This concurs with a study conducted in Ethiopia, where almost all participants rarely or never consumed food that contained high saturated fat. The setting of the current study was a public hospital that mostly attended to the poor population in the area. The majority of patients from low socioeconomic status in Africa cannot afford deep-fried fast foods which are usually sold at "affluent" restaurants. ${ }^{39}$ According to Steyn et al (2011), fast food is regarded as a convenient choice of food accessible to employed people who worked far from home which made it difficult to have all regular homecooked meals throughout the day. ${ }^{39}$ However, the current study was mainly made up of respondents in their old age who were most likely to be pensioners spending most of their time at home where they could have a decent home- 


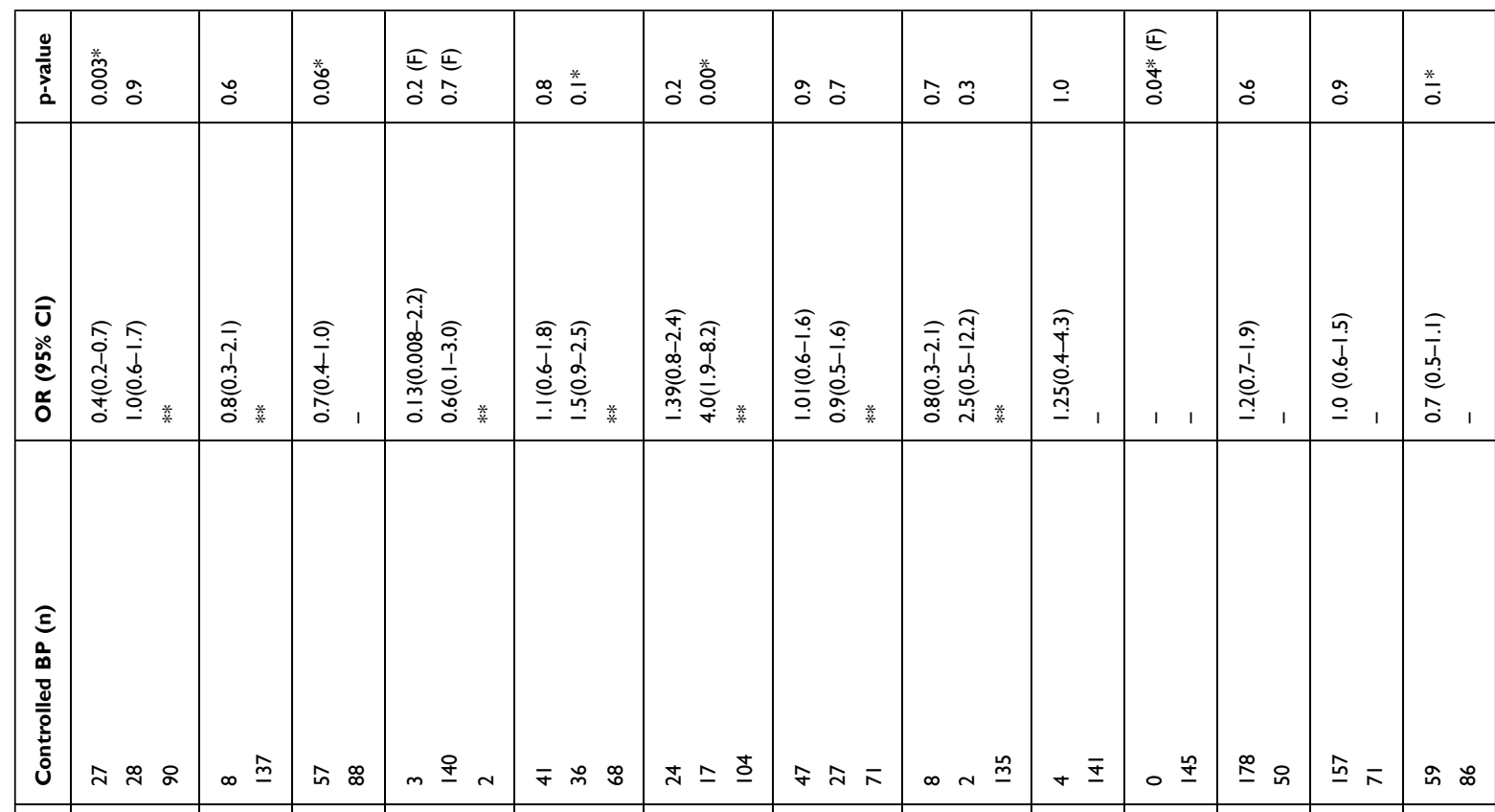

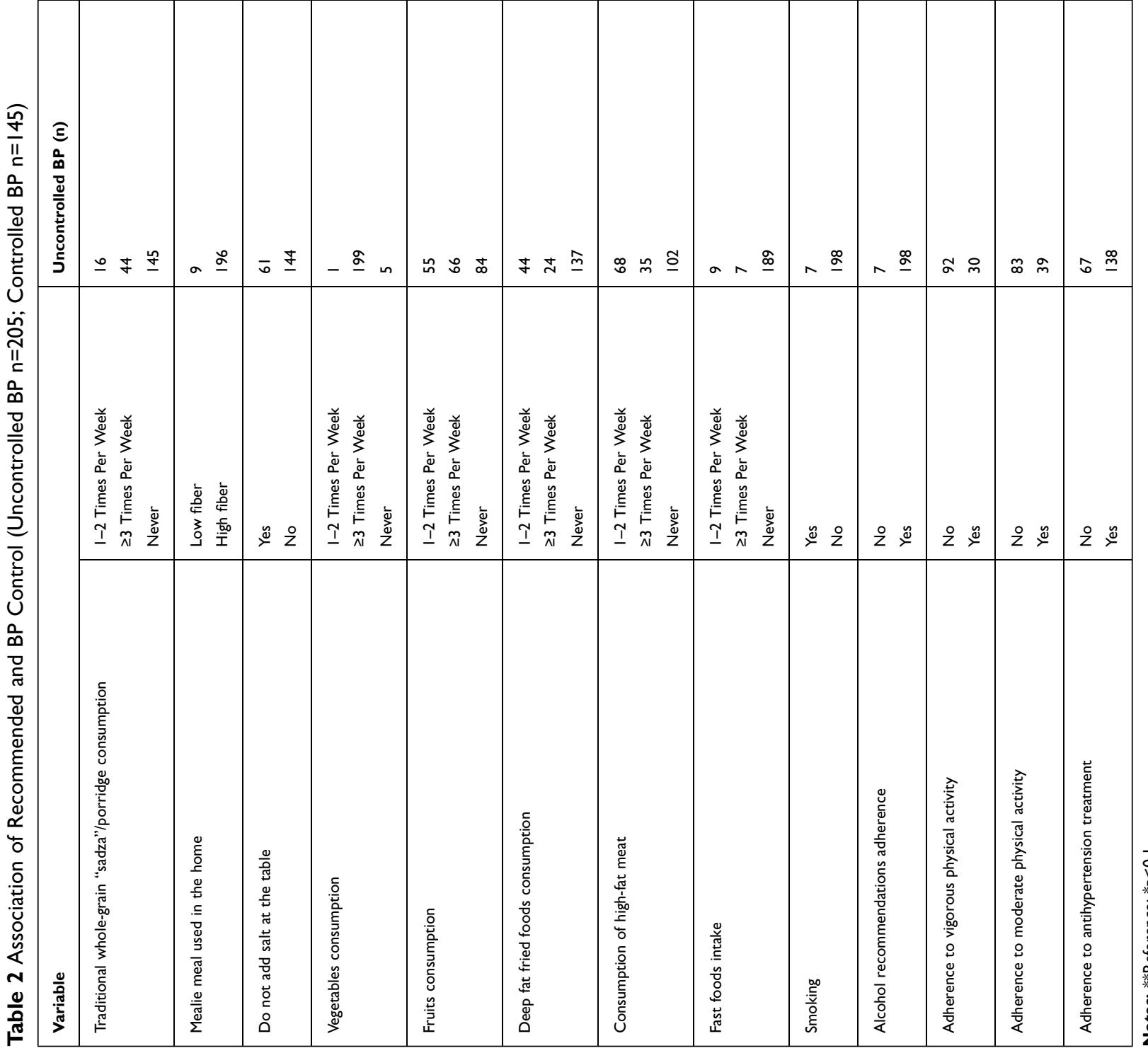



2

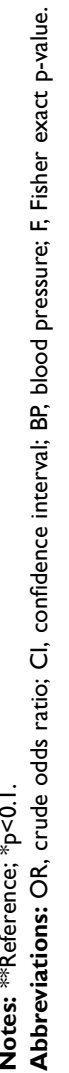


Table 3 Multivariate Logistic Regression Analysis on the Association Between Different Lifestyle Behavior Components and BP Control

\begin{tabular}{|l|l|l|l|}
\hline Variable & AOR & $\mathbf{9 5 \%} \mathbf{C l}$ & $\mathbf{p - v a l u e ~}$ \\
\hline Not adding salt to food when served & 0.6 & $0.4-0.9$ & $0.02 *$ \\
\hline Consuming traditional whole-grain "sadza"/porridge & 1.6 & $1.0-2.5$ & $0.04 *$ \\
\hline Alcohol recommendations & 1.4 & $0.6-3.3$ & 0.5 \\
\hline Consuming deep fat fried foods & 1.2 & $0.8-2.0$ & 0.4 \\
\hline Adherence to antihypertensive treatment & 1.1 & $0.7-1.7$ & 0.7 \\
\hline Fruit consumption & 0.8 & $0.5-1.2$ & 0.2 \\
\hline
\end{tabular}

Note: ${ }^{*} p<0.05$ (result was statistically significant).

Abbreviations: $\mathrm{AOR}$, adjusted odds ratio; $\mathrm{Cl}$, confidence interval.

cooked meal; therefore, few participants consumed purchased refined foods rich in saturated fats. Also, deep-fried foods from restaurants are often viewed as a luxury and are far too expensive when compared to home-cooked meals. This study was limited because the saturated fatcontaining foods were not individually identified and the portion sizes of food consumed were not determined.

Although the association between physical exercise and BP control showed a result that was not statistically significant, the present study noted that most participants did not adhere to both moderate and vigorous physical activity recommendations. A study from Bangladesh also found out that the rate of regular exercise was rarely/never practiced by $77 \%$ of hypertensive patients. ${ }^{40} \mathrm{~A}$ third of the NHANES-III hypertensive patients received counseling to do physical activity to manage their hypertension, $71 \%$ followed the recommendations and had an SBP that was an average of almost equal to $3-4 \mathrm{~mm} \mathrm{Hg}$ lower than their counterparts who did not follow recommendations. ${ }^{41}$ The high rates of physical inactivity could be attributed to participants' lack of enabling organized community infrastructure and limited awareness of the different forms of physical activities they could conduct to control their BP. The majority of participants were old ( $>65$ years), a time when most individuals report having challenges in physical activities due to physiological barriers like pain and discomfort as a result of arthritic joints. Health promotion practitioners like community health workers in the study area can disseminate information on the importance of BP management by moderate and regular physical exercise as tolerated by the patient.

In this study, nearly $97 \%$ of the participants were adherent to smoking recommendations. Some studies, relating to cessation of smoking were conducted in Bangladesh, China, Turkey, and Israel, where most of the participants were found to be adherent. ${ }^{40,42-44}$ Furthermore, other studies support that hypertensive patients had lower smoking rates as a result of awareness of the effect of smoking on hypertension. ${ }^{45}$ In this study of 11 participants smoked cigarettes and 7 of them had uncontrolled BP. However, it should be noted that the association between smoking and BP control was not statistically significant in this study.

About $36 \%$ of the participants were non-adherent to their medication but the relationship between adherence to medication and BP control was statistically insignificant. The participants reported forgetting, missing doses, or failure to follow their medication regimen as instructed by the healthcare worker. Similarly, a meta-analysis that involved 28 studies from 15 countries which comprised 13,688 hypertensive patients reported that $31.2 \%$ of the respondents were found to be non-adherent to medications in 25 of the studies, which involved 12,603 subjects. ${ }^{46}$ Almost similar to the rate found in a study of 149 hypertensive patients, where $42 \%$ and $46.6 \%$ were non-adherent to antihypertensive treatment in the US and Nigeria, respectively. ${ }^{47,48}$ In this population, the non-adherence to medication may be due to recurrent stock-outs of medicines that are very common in public health facilities in Zimbabwe. ${ }^{37}$ In low-income settings like Mutare, the cost of medication can also play a part in nonadherence to medication. With the high cost of antihypertensive medication like calcium channel blockers and ACE inhibitors in Zimbabwe, hypertensive patients sometimes default because they cannot afford to buy the medications at a higher price from private pharmacies.${ }^{49}$ However, there is a need for further probing to ascertain the factors leading to nonadherence to antihypertensive medication since these are multifactorial and the Ministry of Health should ensure consistent availability of subsidized 
antihypertensive treatment at all public hospitals if BP control among the economically disadvantaged is to be achieved.

Of those 18 participants who were adherent to all recommended lifestyle behaviors, 11 had uncontrolled BP. This was an unexpected result and this could be as a result of using a self-reported questionnaire that is liable to reporting bias on some of the variables; thus, the rates of total adherence in our study may be lower than reported. The study finding revealed that the prevalence of controlled BP in the sample was $41.4 \%$. This was consistent with reports from other studies which noted BP control rates of between 34 and $49 \%$. $^{20,50,51}$ Elevated BP is the number one risk factor for cardiovascular diseases and the control and treatment of hypertension can result in a reduced incidence of complications. ${ }^{52}$ Health workers at Mutare Provincial Hospital OPD must devise strategies to promote the control of hypertension among patients. Such interventions should aim at increasing the patient's knowledge of the disease, dispelling inaccurate perceptions towards hypertension, subsidizing the cost of medication while ensuring that the medicines are available at all times.

For a consistent controlled BP, patients must engage in the regular daily performance of the recommended lifestyle behaviors; however, the limited education given to patients on their monthly follow-up visits may not be enough. There is a need for community-based providers who offer a more regular sensitization of the empirically proven behaviors and live in the same community as the patient. To bridge the health system-to-community hypertension treatment gap, the researchers recommend a community-based intervention as proposed by a recent local study that successfully utilized community health workers. ${ }^{53}$ This community-based participatory action research study engaged the community in setting up, planning, and implementation of hypertension awareness, prevention, and treatment intervention. Culturally tailored education by community-based service providers through community hypertension clubs can lead to the primary prevention, treatment, and control of hypertension together with positive lifestyle behavior change among people living with hypertension. ${ }^{54}$

\section{Study Limitations}

The temporal association between some interview question responses and $\mathrm{BP}$ control was not assessed due to the cross-sectional nature of the study. This study did not seek clarity in some areas, for instance, it was not clear whether those who added salt at the table started doing so before their hypertension was uncontrolled or vice-versa.
The responses were self-reported, thus they could have been influenced by the desire to give socially desirable answers. Besides, the type and length of medication being used by participants were not investigated in this study and this may be a source of confounding covariates that influenced analysis. However, there was an attempt to adjust for the length of time a participant had been on medication by including only those who had been on medication for at least six months.

\section{Conclusion}

Overall, adherence to moderate alcohol intake, smoking and high fiber diet were satisfactory while compliance with sodium intake and antihypertensive treatment was fair, adherence to physical exercise was poor. The health workers attending to hypertensive patients should include comprehensive health education messages of all the five lifestyle behaviors though particularly emphasizing physical activity, sodium intake, and the consumption of whole grains when counseling hypertensive patients. Integrated community-based hypertension control activities implemented through the community-based providers can help improve BP control with a minimal increase in resources needed in this resource-constrained setting. The intervention crafting process should focus on identifying enablers of the recommended lifestyle behaviors within the community.

\section{Abbreviations}

BP, blood pressure; CVDs, cardiovascular diseases; DBP, diastolic blood pressure; LMICs, low- and middle-income countries; NCDs, non-communicable diseases; SBP, systolic blood pressure; WHO, World Health Organization.

\section{Acknowledgments}

We are grateful to the Manicaland Provincial Medical Directorate Office, the Executive at Mutare Provincial Hospital, and the clinical team from the Mutare Provincial Hospital OPD for their cooperation and support as well as the study participants for their time. We also acknowledge Africa University Clinical Research Centre for the technical support.

\section{Disclosure}

The authors report no conflicts of interest in this work. 


\section{References}

1. Stolbrink M, Mortimer K. Collision of communicable and non-communicable disease epidemics - the case of HIV and COPD. Lancet Glob Health. 2018;6(2):e126-e127. doi:10.1016/S2214-109X(17)30489-8

2. World Health Organization. Cardiovascular disease in the African region: current situation and perspectives. Geneva: World Health Organization; 2005. Available from: http://apps.who.int/iris/bit stream/10665/1871/1/AFR\%20RC55-12.pdf. Accessed April 4, 2019.

3. Zhou B, Bentham J, Di Cesare M, et al. Worldwide trends in blood pressure from 1975 to 2015: a pooled analysis of 1479 populationbased measurement studies with 19.1 million participants. Lancet. 2017;389(10064):37-55.

4. World Health Organization. Global Status Report on NonCommunicable Diseases. Geneva: World Health Organization; 2011.

5. Lawes CM, Vander Hoorn S, Rodgers A. International society of hypertension. Global burden of blood-pressure-related diseases, 2001. Lancet. 2008;371(9623):1513-1518. doi:10.1016/S0140-6736(08)60655-8

6. Center for Disease Control and Prevention. Heart Disease. U.S. Department of Health \& Human Services. CDC.gov; 2021. Available from: https://www.cdc.gov/heartdisease/american_heart_ month_patients.htm. Accessed May 8, 2021.

7. Siu AL. Screening for abnormal blood glucose and type 2 diabetes mellitus: U.S. preventive services task force recommendation statement. Ann Intern Med. 2015;163(11):861-869. doi:10.7326/M152345

8. Shackelford K. Uncontrolled hypertension increases risk of chronic disease. Very-Well Health; 2018. Available from: https://www.very wellhealth.com/complications-of-hypertension-1763820. Accessed March 22, 2019.

9. Smit M, Olney J, Ford NP, et al. The growing burden of non-communicable disease among persons living with HIV in Zimbabwe. AIDS. 2018;32(6):773-782. doi:10.1097/QAD.0000000000001754

10. Whitworth JA; World Health Organization, International Society of Hypertension Writing Group. World Health Organization (WHO)/ International Society of Hypertension (ISH) statement on management of hypertension. J Hypertens. 2003;21(11):1983-1992.

11. Viera AJ, Kshirsagar AV, Hinderliter AL. Lifestyle modifications to lower or control high blood pressure: is advice associated with action? The behavioral risk factor surveillance survey. J Clin Hypertens. 2008;10 (2):105-111. doi:10.1111/j.1751-7176.2008.07577.x

12. Adeloye D, Basquill C, Schnabel RB. Estimating the prevalence and awareness rates of hypertension in Africa: a systematic analysis. PLoS One. 2014;9(8):e104300. doi:10.1371/journal.pone.0104300

13. Geldsetzer P, Manne-Goehler J, Marcus ME, et al. The state of hypertension care in 44 low-income and middle-income countries: a cross-sectional study of nationally representative individual-level data from 1.1 million adults. Lancet. 2019;394(10199):652-662. doi:10.1016/S0140-6736(19)30955-9

14. Kaiser AH, Hehman L, Forsberg BC, Simangolwa WM, Sundewall J. Availability, prices and affordability of essential medicines for the treatment of diabetes and hypertension in private pharmacies in Zambia. PLoS One. 2019;14(12):e0226169. doi:10.1371/journal. pone. 0226169

15. Htay H, Alrukhaimi M, Ashuntantang GE, et al. Global access of patients with kidney disease to health technologies and medication: findings from the global kidney health atlas project. Kidney Int Suppl. 2018;8(2):64-73. doi:10.1016/j.kisu.2017.10.010

16. Wang Q, Fu AZ, Brenner S, Kalmus O, Banda HT, De Allegri M. Out-of-pocket expenditure on chronic non-communicable diseases in sub-Saharan Africa: the case of rural Malawi. PLoS One. 2015;10(1): e0116897. doi:10.1371/journal.pone.0116897

17. Mutowo MP, Mangwiro JC, Lorgelly P, Owen A, Renzaho AM. Hypertension in Zimbabwe: a meta-analysis to quantify its burden and policy implications. World $J$ Metaanal. 2015;3(1):54-60. doi:10.13105/wjma.v3.i1.54
18. Mufunda J, Chatora R, Ndambakuwa Y, et al. Prevalence of noncommunicable diseases in Zimbabwe: results from analysis of data from the national central registry and urban survey. Ethn Dis. 2006;16(3):718-722.

19. Im SI, Rha SW, Choi BG, Choi SY, Lee JJ. Impact of uncontrolled hypertension on 12-month clinical outcomes following below-theknee arteries (BTK) interventions in patients with critical limb ischemia. Clin Hypertens. 2016;22. doi:10.1186/s40885-016-0044-y

20. Tibebu A, Mengistu D, Negesa L. Adherence to recommended lifestyle modifications and factors associated for hypertensive patients attending chronic follow-up units of selected public hospitals in Addis Ababa, Ethiopia. Patient Prefer Adherence. 2017;11:323330. doi:10.2147/PPA.S126382

21. Mukora-Mutseyekwa FN, Chadambuka EM. Drug adherence behavior among hypertensive out-patients at a tertiary health institution in Manicaland Province, Zimbabwe, 2011. Patient Prefer Adherence. 2013;7:65-70. doi:10.2147/PPA.S40295

22. Joint National Committee. 8 Guidelines for the management of hypertension in adults. Am Fam Physician. 2014;90(7):503-504.

23. Pickering TG, Hall JE, Appel LJ, et al. Recommendations for blood pressure measurement in humans and experimental animals: part 1: blood pressure measurement in humans: a statement for professionals from the subcommittee of the professional and public education of the American heart association council on high blood pressure research. Circulation. 2005;111:697-716. doi:10.1161/01. CIR.0000154900.76284.F6

24. Parati G, Stergiou G, O'Brien E, et al. European Society of hypertension practice guidelines for ambulatory blood pressure monitoring. $J$ Hypertens. 2014;32(7):1359-1366. doi:10.1097/ HJH.0000000000000221

25. Handler J, Zhao Y, Egan BM. Impact of the number of blood pressure measurements on blood pressure classification in US adults: NHANES 1999-2008. J Clin Hypertens (Greenwich). 2012;14 (11):751-759. doi:10.1111/jch.12009

26. Pierin AMG. Nursing and research in arterial hypertension. Acta Paul Enferm. 2010;23(5):7-8.

27. Health Development Agency. Manual for the fast alcohol screening test (FAST): fast screening for alcohol problems. Development. 2002;12(3):1-14.

28. Obirikorang Y, Obirikorang C, Acheampong E, et al. Adherence to lifestyle modification among hypertensive clients: a Descriptive Cross-Sectional Study. OALib J. 2018;5(2):1-13. doi:10.4236/ oalib. 1104375

29. Weinberger MH. Salt sensitivity of blood pressure in humans. Hypertens. 1996;27(3):481-490. doi:10.1161/01.HYP.27.3.481

30. BMJ. Effects of dose and duration of reduction in dietary sodium on blood pressure levels: systematic review and meta-analysis of randomized trials. BMJ. 2020;368:m315.

31. Sacks FM, Svetkey LP, Vollmer LM. Effects on blood pressure of reduced dietary sodium and the dietary approaches to stop hypertension (DASH) diet. $N$ Engl J Med. 2001;344(1):3-10. doi:10.1056/ NEJM200101043440101

32. Kashino I, Eguchi M, Miki T, et al. Prospective association between whole grain consumption and hypertension: the Furukawa Nutrition and Health Study. Nutrients. 2020;12(4):902. doi:10.3390/nu12040902

33. Schingshackl L, Schwedhelm C, Hoffman G, et al. Food groups and risk of hypertension: a systematic review and dose-response metaanalysis of prospective studies. Adv Nutr. 2017;8(6):793-803. doi:10.3945/an.117.017178

34. Dzomba P, Gwatidzo L, Mugari P, Mupa M. Traditional dishes consumed in Zimbabwe and high-performance liquid chromatography (HPLC) quantitation of their antioxidant phytochemicals. Afr $J$ Biotechnol. 2017;16(26):1461-1473.

35. Wang L, Chen J, Xie H, Ju X, Liu RH. Phytochemical profiles and antioxidant activity of adlay varieties. J Agric Food Chem. 2013;61 (21):5103-5113. doi:10.1021/jf400556s 
36. Marques FZ, Nelson E, Chu PY, et al. High-fiber diet and acetate supplementation change the gut microbiota and heart failure in hypertensive mice. Circulation. 2017;135(10):964-977. doi:10.1161/ CIRCULATIONAHA.116.024545

37. Chimberengwa PT, Naidoo M, Isangula KG; Cooperative Inquiry Group. Knowledge, attitudes and practices related to hypertension among residents of a disadvantaged rural community in southern Zimbabwe. PLoS One. 2019;14(6):e0215500. doi:10.1371/journal. pone. 0215500

38. Gonde LL, Chimbari MJ. Community awareness of diet needs associated with hypertension and type 2 diabetes mellitus in Hatcliffe, Zimbabwe. BMC Public Health. 2019;19(1686). doi:10.1186/s12889019-8030-4

39. Steyn NP, Labadarios D, Nel JH. Factors which influence the consumption of street foods and fast foods in South Africa- a national survey. BMC Nutr. 2011;10(104).

40. Akhter N. Self-Management Among Patients with Hypertension in Bangladesh [unpublished master degree thesis]. Thailand: Faculty of Nursing. Prince of Songkla University; 2010.

41. Halm J, Amoako E. Physical activity recommendation for hypertension management: does healthcare provider advice make a difference? Ethn Dis. 2008;18(3):278-282.

42. $\mathrm{Hu} \mathrm{H}$, Li G, Arao T. Prevalence rates of self-care behaviors and related factors in a rural hypertension population: a questionnaire survey. Int $J$ Hypertens. 2013;2013:526949. doi:10.1155/2013/ 526949

43. Danaei G, Finucane MM, Lin JK, et al. National, regional, and global trends in systolic blood pressure since 1980: systematic analysis of health examination surveys and epidemiological studies with 786 country-years and $5 \cdot 4$ million participants. Lancet. 2011;377 (9765):568-577. doi:10.1016/S0140-6736(10)62036-3

44. Heymann AD, Gross R, Tabenkin H, Porter B, Porath A. Factors associated with hypertensive patients' compliance with recommended lifestyle behaviors. Isr Med Assoc J. 2011;13(9):553-557.

45. Jaddou H, Batieha A, Khader Y, Kanaan A, El-Khateeb M, Ajlouni K. Hypertension prevalence, awareness, treatment and control, and associated factors: results from a national survey, Jordan. Int $J$ Hypertens. 2011;2011:ID828787. doi:10.4061/2011/828797
46. Abegaz TM, Shehab A, Gebreyohannes EA, Bhagavathula AS, Elnour AA. Non-adherence to antihypertensive drugs. Medicine. 2017;96(4). doi:10.1097/MD.0000000000005641

47. Gallagher BD, Muntner P, Moise N, Lin JJ, Kronish IM. Are two commonly used self-report questionnaires useful for identifying antihypertensive medication non-adherence? J Hypertens. 2015;33 (5):1108-1113. doi:10.1097/HJH.0000000000000503

48. Adisa R, Ilesanmi OA, Fakeye TO. Treatment adherence and blood pressure outcome among hypertensive out-patients in two tertiary hospitals in Sokoto, Northwestern Nigeria. BMC Cardiovasc Disord. 2018;18(1):194. doi:10.1186/s12872-018-0934-x

49. Gowera TP, Masuka N, Tshimanga M, et al. Uncontrolled hypertension among hypertensive patients on treatment in Lupane District, Zimbabwe, 2012. BMC Res Notes. 2014;7(703).

50. Kimani S, Mirie W, Chege M, Okube OT, Muniu S. Association of lifestyle modification and pharmacological adherence on blood pressure control among patients with hypertension at Kenyatta National Hospital, Kenya: a Cross-Sectional Study. BMJ Open. 2019;9(1): e023995. doi:10.1136/bmjopen-2018-023995

51. Ministry of Health (Ministerio de Salud, MINSAL). National health survey, Chile (1). Santiago, 2009-2010. Available from: http://web. minsal.cl/search/node/Encuesta\%20MINSAL. Accessed May 5, 2021.

52. Kearney PM, Whelton M, Reynolds K, Whelton PK, He J. Worldwide prevalence of hypertension: a systematic review. $J$ Hypertens. 2004;22(1):11-19. doi:10.1097/00004872-20040100000003

53. Chimberengwa PT, Naidoo M. A description of community-based participatory research of hypertension awareness, prevention and treatment in a district of Matabeleland South Province, Zimbabwe. Afr J Prim Health Care Fam Med. 2019;11(1):a1839. doi:10.4102/ phcfm.v11i1.1839

54. Pioane TR, Tsolekile L, Igumbor EU, Fourie JM. Experiences in developing and implementing health clubs to reduce hypertension risk among adults in a South African population in transition. Int $J$ Hypertens. 2012;913960.
Patient Preference and Adherence

\section{Publish your work in this journal}

Patient Preference and Adherence is an international, peer-reviewed, open access journal that focusing on the growing importance of patient preference and adherence throughout the therapeutic continuum. Patient satisfaction, acceptability, quality of life, compliance, persistence and their role in developing new therapeutic modalities and compounds to optimize clinical outcomes for existing disease states are major areas of interest for the journal. This journal has been accepted for indexing on PubMed Central. The manuscript management system is completely online and includes a very quick and fair peer-review system, which is all easy to use. Visit http:// www.dovepress.com/testimonials.php to read real quotes from published authors. 